\title{
Nanopartículas de óxido de zinco sintetizadas pelo método poliol: caracterização e avaliação da atividade antibacteriana
}

\section{Zinc oxide nanoparticles synthesized by the polyol method:characterization and evaluation of the antibacterial activity}

Renato Cesar Tobias Porto ${ }^{1}$, Patrícia Zigoski Uchôa ${ }^{1}$, Lana Taíse Peschel ${ }^{1}$, Bruno Justi ${ }^{1}$, Luciano André Deitos Koslowski ${ }^{2}$, André Lourenço Nogueira ${ }^{1}$

\author{
${ }^{1}$ Universidade da Região de Joinville - UNIVILLE. Curso de Engenharia Química e Mestrado em Engenharia de Proces- \\ sos, Rua Paulo Malschitzki, 10 - Zona Industrial Norte, Joinville - SC; \\ ${ }^{2}$ Universidade e do Estado de Santa Catarina- UDESC, Departamento de Engenharia Sanitária -Ibirama. e-mail: noguei- \\ ra.a.1@hotmail.com; rctporto@hotmail.com
}

\section{RESUMO}

A utilização de materiais nanoestruturados sintetizados a partir de sais metálicos tem atraído cada vez mais a atenção de pesquisadores e indústrias no sentido de desenvolver aplicações inovadoras em áreas como a de energia, saúde e alimentos. A prata, o cobre e o óxido de zinco, por apresentarem propriedades antibacterianas, possuem um grande potencial para aplicação como substituintes aos tradicionais agentes antibacterianos organoclorados e derivados de arsênio. O óxido de zinco, por apresentar baixíssima toxicidade às células humanas, não sendo classificado como metal pesado e por ser um material biocompatível, aparece como alternativa em aplicações como na área médica e no tratamento de água para o consumo. O presente trabalho teve como principal objetivo sintetizar nanopartículas de óxido de zinco pelo método do poliol, e avaliar a atividade antibacteriana destas nanoestruturas contra a bactéria Gram negativa Escherichia coli. As sínteses foram conduzidas na presença e ausência da poli(vinil pirrolidona) para investigar a influência deste agente estabilizante nas propriedades morfológicas das nanopartículas obtidas. Todas as amostras foram caracterizadas por espectrofotometria na região do UV-Vis, difratometria de raios$\mathrm{X}$, microscopia eletrônica de varredura com efeito de campo e microscopia eletrônica de transmissão. Testes para avaliação da atividade antibacteriana com diferentes quantidades de nanopartículas de óxido de zinco sintetizadas sem a poli(vinil pirrolidona) foram conduzidos conforme a norma ASTM E-2149. Os resultados obtidos demonstraram que o método do poliol foi capaz de produzir nanopartículas de óxido de zinco com elevado grau de pureza e diâmetro médio em torno de $20 \mathrm{~nm}$, na ausência ou presença da poli(vinil pirrolidona). Os ensaios microbiológicos comprovaram que as nanopartículas de óxido de zinco produzidas apresentaram excelente atividade antibacteriana contra a bactéria Escherichia coli quando aplicadas em concentrações superiores a $50 \mathrm{mg} \cdot \mathrm{L}^{-1}$.

Palavras-chave: nanopartículas de óxido de zinco, atividade antibacteriana, método do poliol, tratamento de água.

\begin{abstract}
The use of nanostructured materials synthesized from metal salts has increasingly attracted the attention of researchers and industries to develop innovative applications in areas such as energy, health and food. Due to the antibacterial properties of silver, copper and zinc oxide, they are potential substituents to the traditional antibacterial agents, such as organochlorines and arsenic derivatives. Once zinc oxide is not classified as heavy meta, has low toxicity, and is biocompatible, it appears as an alternative material for applications in the medical area and water treatment. The main objective of this work was to synthesize zinc oxide nanoparticles by the polyol method and evaluate the antibacterial activity of these nanostructures against the Gram negative bacteria Escherichia coli. The syntheses were carried out in the presence and absence of poly(vinyl pyrrolidone) to investigate the influence of this stabilizing agent on the morphological properties of the
\end{abstract}


nanoparticles. All of the samples were characterized by UV-Vis spectrophotometry, X-ray diffractometry, field emission scanning electron microscopy and transmission electron microscopy. Tests to evaluate the antibacterial activity of different amounts of the zinc oxide nanoparticles were performed according to the ASTM E-2149. The results obtained demonstrated that the polyol method was able to produce zinc oxide nanoparticles with high purity and average diameter around $20 \mathrm{~nm}$, regardless the presence of poly(vinyl pyrrolidone). Microbiological assays showed that zinc oxide nanoparticles produced excellent antibacterial activity against the bacteria Escherichia coli when applied at concentrations higher than $50 \mathrm{mg} \cdot \mathrm{L}^{-1}$.

Keywords: nanoparticles, zinc oxide, antibacterial activity, polyol method, water treatment.

\section{INTRODUÇÃO}

O desenvolvimento e a aplicação prática de nanotecnologias têm atraído cada vez mais a atenção das indústrias e de pesquisadores devido às notáveis propriedades que se pode alcançar com os materiais quando o de tamanho das partículas atinge a escala nanométrica [1]. No que concerne o desenvolvimento de nanoestruturas com propriedades antibacterianas para aplicações diversas, é possível encontrar na literatura trabalhos envolvendo o uso de nanopartículas de prata [2], cobre [3], óxido de zinco [4], dióxido de titânio [5] e dióxido de estanho [6]. O uso de nanopartículas metálicas para aplicação como agentes antibacterianos aparece como uma importante alternativa aos tradicionais organoclorados e aos derivados de arsênio, usualmente empregados para esta finalidade. Além disso, o uso de nanopartículas é extremamente vantajoso do ponto de vista da eficácia do produto, pois a elevada relação entre e área superficial e o volume exibida pelas nanopartículas permite que mínimas quantidades destes materiais sejam suficientes para conferir excelentes propriedades antibacterianas [2].

Em comparação aos compostos orgânicos, as nanopartículas de óxido de zinco são extremamente vantajosas, pois além de apresentarem uma atividade antibacteriana mais durável, são resistentes ao calor [7], o que permite sua aplicação em processos como o de transformação de plásticos. Entre os diversos materiais nanoestruturados utilizados como agentes antimicrobianos, o óxido de zinco vem recebendo cada vez mais atenção não só devido a sua excelente eficiência bactericida e fungicida, mas também por não ser classificado como um metal pesado, como é o caso da prata. Além de ser um material que apresenta baixíssima toxicidade aos seres humanos, é seguro e biocompatível [4], o que permite seu uso como agente ativo em medicamentos para aplicação dermatológica devido a sua atividade antimicrobiana [8]. Atualmente é possível encontrar aplicações do óxido de zinco nas indústrias farmacêutica (pomadas ou pós antisépticos), cosmética (desodorantes e protetores solares) [9] e de alimentos (embalagens ativas para aumento do tempo de prateleira de produtos) [10].

$\mathrm{Na}$ forma de nanopartículas, o óxido de zinco é efetivo no controle de uma grande quantidade de microrganismos, pois apresenta a capacidade de alterar os componentes da membrana celular da bactéria, distorcendo-a e rompendo-a, o que leva à perda do componente intracelular e a consequente morte do microorganismo [11]. Por esta razão, nanopartículas de óxido de zinco vem sendo cada vez mais estudadas e utilizadas em aplicações nas quais propriedades antibacterianas são requeridas. Uma potencial área de aplicação para estas nanopartículas é a biomédica, na qual existe a problemática do desenvolvimento de bactérias resistentes a antibióticos. Outra área promissora para a aplicação das nanopartículas de óxido de zinco, e que é de grande interesse mundial, é a desinfecção de águas para o consumo humano. Dentre os patógenos mais comuns encontrados na água, a Escherichia coli (E. coli) está entre os mais nocivos, pois pode causar inflamação do cólon, diarréia, dores abdominais e, nos casos mais graves, a evacuação de sangue [4]. Atualmente existem estudos [12], [13] e [14] e até mesmo produtos comerciais que usam prata coloidal para aniquilar bactérias em unidades de tratamento de água. Contudo, o uso da prata é questionável do ponto de vista de toxicidade, tanto aos serem humanos quanto ao próprio meio ambiente.

Neste contexto, o uso de nanopartículas de óxido de zinco, em detrimento ao uso das nanopartículas de prata, aparece como uma alternativa viável, saudável e ecologicamente correta para o desenvolvimento de filtros com propriedades antibacterianas. Desta forma, o presente trabalho teve como principal objetivo sintetizar, caracterizar, e avaliar a atividade antibacteriana de nanopartículas de óxido de zinco contra a bactéria Gram negativa $E$. coli, vislumbrando a possibilidade de aplicação destas nanoestruturas no tratamento de água para o consumo humano. 


\section{MATERIAIS E MÉTODOS}

\subsection{Síntese das nanopartículas}

As nanopartículas de óxido de zinco foram preparadas utilizando-se acetato de zinco dihidratado $\left(\mathrm{CH}_{3} \mathrm{COO}\right)_{2} \mathrm{Zn} \cdot 2 \mathrm{H}_{2} \mathrm{O}(99,995 \%$, Quiminorte) como sal precursor, monoetilenoglicol (Quimidrol) como veículo do meio reacional, poli(vinil pirrolidona) - PVP $\left(\mathrm{MM}=55.000 \mathrm{~g} \cdot \mathrm{mol}^{-1}\right.$, Sigma-Aldrich) como agente estabilizante, e água deionizada como iniciador das reações de hidratação e condensação responsáveis pela nucleação das nanopartículas. Todos os reagentes foram utilizados conforme recebido, sem purificação prévia.

De acordo com [15], a água pode agir não só como reagente na reação de hidrólise (equação 1), mas também como produto na reação de condensação (equação 2 b). Com isso, a razão de hidratação pode afetar tanto a taxa de hidrólise quanto a taxa de condensação do precursor do $\mathrm{Zn}$ na solução, através da qual partículas de $\mathrm{ZnO}$ podem ser nucleadas para, posteriormente, crescerem. O autor ainda relata que os íons acetato do sal precursor podem ser fortemente quelados aos íons $\mathrm{Zn}^{+2}$, de forma que o acetato de zinco não consegue se dissociar totalmente na solução, permanecendo na forma de $\mathrm{Zn}\left(\mathrm{CH}_{3} \mathrm{COO}\right)_{2 \text { (aq.). }}$ Com a introdução da água, o $\mathrm{Zn}\left(\mathrm{CH}_{3} \mathrm{COO}\right)_{2 \text { (aq.) }}$ pode se hidrolisar, dando origem ao composto intermediário $\mathrm{Zn}(\mathrm{OH})\left(\mathrm{CH}_{3} \mathrm{COO}\right)$ (equação 1). A reação de condensação envolvendo este composto hidrolisado pode ocorrer por dois mecanismos possíveis, de modo que a ligação $\mathrm{Zn}-\mathrm{O}-\mathrm{Zn}$ se forme, resultando na liberação de $\mathrm{CH}_{3} \mathrm{COOH}$ (equação 2.a) ou $\mathrm{H}_{2} \mathrm{O}$ (equação 2.b). A nucleação do $\mathrm{ZnO}$ ocorre por meio de sucessivas reações de hidrólise e condensação da espécie intermediária formada nas reações apresentadas nas equações $2 \mathrm{a}$ e $2 \mathrm{~b}$ (equação 3). Uma vez que a nucleação ocorre, as partículas crescem devido à adição das espécies intermediárias. Este modelo de crescimento por adição requer a hidrólise do complexo de $\mathrm{Zn}$ precursor na superfície das partículas em crescimento. O mecanismo reacional completo é apresentado a seguir nas equações numeradas de 1 a 3 :

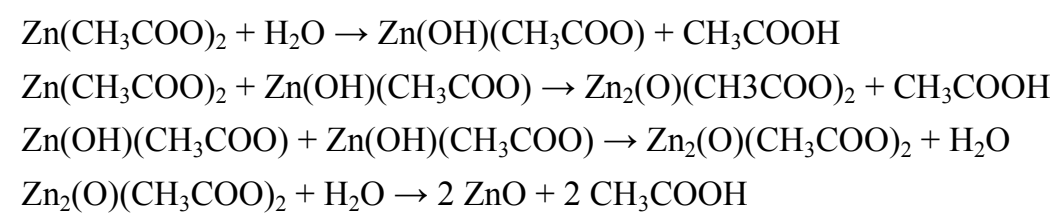

As sínteses das nanopartículas de óxido de zinco foram realizadas em um balão volumétrico com 3 bocas de $250 \mathrm{ml}$ com um condensador de refluxo instalado para evitar o escape de gases. Inicialmente, adicionou-se no sistema reacional o monoetilenoglicol $(100 \mathrm{~mL})$, seguido pelo acetato de zinco di-hidratado $(8,76 \mathrm{~g})$, e o sistema foi mantido sob vigorosa agitação a temperatura ambiente até a completa solubilização do sal precursor. Em seguida, nas sínteses que foram conduzidas na presença do agente estabilizante, adicionou-se 1,0 g de poli(vinil pirrolidona) seguido de 1,0 $\mathrm{mL}$ de água deionizada. Em paralelo, uma amostra foi sintetizada sem o uso de agente estabilizante, sendo adicionado apenas 1,0 $\mathrm{mL}$ de água deionizada após a solubilização do sal precursor. Em seguida, cada mistura reacional foi submetida a uma vigorosa agitação, e aquecida até $205^{\circ} \mathrm{C}$, mantendo estas condições por 220 minutos. Após este período, os meios reacionais foram resfriados naturalmente até atingirem a temperatura ambiente. Posteriormente, as partículas produzidas foram suspensas em acetona (Dinâmica) na proporção 1:3, e submetidas a sucessivas etapas de centrifugação a 3500 RPM e $25^{\circ} \mathrm{C}$ por 30 minutos (centrífuga marca Sigma, modelo $3 \mathrm{k} 12$ ). Um vez lavados e separados, os produtos foram submetidos à secagem em estufa por 24 horas à $50^{\circ} \mathrm{C}$, para então serem caracterizados.

\subsection{Caracterização das nanopartículas}

As caracterizações por espectrofotometria de UV-Vis foram realizadas preparando suspensões das partículas secas de óxido de zinco em água deionizada numa proporção de 0,01g de sólidos para 100,0 mL de água. Em seguida, esta suspensão foi homogeinizada em um banho de ultrassom por 30 minutos e transferida para uma cubeta de quartzo com caminho óptico de $10 \mathrm{~mm}$. Os valores de absorção foram lidos em um espectrofotômetro Shimadzu UV-1601PC, com o intuito de se avaliar e comparar com a literatura os espectros de absorção de luz na região do ultravioleta das partículas de óxido de zinco sintetizadas.

As análises de microscopia eletrônica de varredura por emissão de campo (MEV-FEG) foram realizadas em um microscópio JEOL - JSM 6701 operando com $10 \mathrm{kV}$. As amostras de nanopartículas secas 
foram aderidas em uma fita adesiva dupla face sobre o suporte, retirando o excesso de partículas com ar comprimido, e posteriormente recobertas por uma fina camada de ouro. Para as análises de microscopia eletrônica de transmissão (MET), 1,0 g das amostras de nanopartículas foram suspensas em $10 \mathrm{~mL}$ de água deionizada, e dispersas em um banho de ultrassom durante 30 minutos. Em seguida, 10 gotas de cada amostra foram pingadas em grids de cobre de 300 mesh recobertos com filme de carbono. As imagens foram realizadas em um microscópio eletrônico de transmissão JEOL JEM-2100 operando com resolução de 200 $\mathrm{kV}$ para realização das imagens.

Análises de difratometria de raios-X foram conduzidas para se avaliar a estrutura cristalográfica das partículas sintetizadas. Para isso, utilizou-se o equipamento Philips X'pert operando com radiação $\mathrm{CuK} \alpha$ de $40 \mathrm{kV}, 30 \mathrm{~mA}(\lambda=1,5406 \AA)$ e um passo de $0,02^{\circ}$. As leituras foram realizadas com ângulo de difração variando entre 30 e $90^{\circ}$.

\subsection{Testes antibacterianos}

Os testes para avaliação da atividade antibacteriana das nanopartículas de óxido de zinco foram realizados com base na norma ASTM E2149 - Determinação da Atividade Antimicrobiana de Agentes Antimicrobianos Imobilizados sob Condições de Contato Dinâmico". A bactéria Gram negativa Escherichia coli (CCT-8739) foi selecionada para os ensaios pelo fato desta bactéria estar diretamente relacionada a problemas de saúde gerados pelo consumo de água contaminada. Os ensaios antibacterianos foram realizados com concentrações de $0,25,50$ e $100 \mathrm{mg} . \mathrm{L}^{-1}$ das nanopartículas de óxido de zinco sintetizadas sem poli(vinil pirrolidona).

O inóculo foi preparado solubilizando-se $0,8 \mathrm{~g}$ de ágar bacteriológico em $100 \mathrm{~mL}$ de água destilada. Depois de autoclavada durante $15 \mathrm{~min}$. a $121^{\circ} \mathrm{C}$, esta solução foi resfriada para que uma determinada quantidade das bactérias E.coli fosse adicionada. Esta solução foi incubada por 18 horas na temperatura de 37 ${ }^{\circ} \mathrm{C}$ e agitação de 130 RPM. O preparo do cultivo sólido foi realizado pela diluição, sob agitação, de $22 \mathrm{~g}$ de caldo Mueller Hinton em $1000 \mathrm{~mL}$ de água destilada, seguido de aquecimento e autoclavagem nas mesmas condições do inóculo. Esta solução foi acondicionada em placas de Petri para solidificação em uma capela de fluxo laminar previamente esterilizada com radiação ultravioleta, tampadas e lacradas com parafilm.

Para a realização do teste antibacteriano, o inóculo foi diluído até que fosse atingida uma leitura de absorbância de $0,28 \pm 0,1$ no comprimento de onda de $475 \mathrm{~nm}$ em espectrofotômetro (SP-22 BIOSPECTRO). A seguir, a amostra foi submetida a uma diluição seriada até se alcançar uma concentração de $1,5-3,0 \times 10^{5}$ UFC $/ \mathrm{mL}$. A amostra de referência foi preparada adicionando-se apenas $50 \mathrm{~mL}$ do inóculo diluído em um Erlenmeyer de $100 \mathrm{~mL}$.

Para se avaliar a eficiência antibacteriana das nanopartículas de óxido de zinco obtidas neste trabalho, três amostras foram preparadas em erlenmeyers diferentes, cada um contendo $50 \mathrm{~mL}$ do inóculo mais $10 \mathrm{~mL}$ de uma solução aquosa contendo distintas quantidades de óxido de zinco. Estas soluções aquosas foram preparadas dispersando $0,125 \mathrm{~g}, 0,25 \mathrm{~g}$ e $0,50 \mathrm{~g}$ de óxido de zinco nanoparticulado em $10 \mathrm{~mL}$ de água deionizada. Estas suspensões aquosas foram adicionadas em $50 \mathrm{~mL}$ do inóculo, resultando em suspensões com teor de óxido de zinco de 25, 50 e $100 \mathrm{mg} . \mathrm{L}^{-1}$, repectivamente, as quais foram dispersas em banho de ultrassom por 30 minutos.

Após 24 horas sob agitação em shaker, e temperatura controlada de $37^{\circ} \mathrm{C}$, as amostras foram novamente diluídas até atingirem uma concentração de 1,0 × $10^{3} \mathrm{UFC} / \mathrm{mL}$. Em tréplicas, alíquotas de $0,1 \mathrm{~mL}$ foram espalhadas sobre a superfície do ágar nas placas de Petri, com auxílio de uma alça triangular de vidro Drigalski, até a completa absorção. As placas foram incubadas a $37^{\circ} \mathrm{C}$ por 24 horas e, posteriormente foi realizada a contagem das unidades formadoras de colônias (UFC).

\section{RESULTADOS E DISCUSSÕES}

De acordo com a Figura 1, referente a amostra de nanopartículas sintetizadas sem a presença de poli(vinil pirrolidona), observa-se uma pronunciada absorção no comprimento de onda de $360 \mathrm{~nm}$, condizentes com os resultados reportados por [16].

O espectro da amostra sintetizada na presença de poli(vinil pirrolidona) apresentou resultados semelhantes ao anterior, tendo sua maior absorção em aproximadamente $360 \mathrm{~nm}$. Porém, as amostras sintetizadas com poli(vinil pirrolidona) absorveram mais radiação do que aquelas sintetizadas sem este agente estabilizante, o que é um indício de que houve uma melhor dispersão das nanopartículas no meio aquoso e uma melhor manutenção da estabilidade coloidal, o que contribuiu para que um número maior de nanopartículas permanecesse em suspensão durante a realização da análise. 


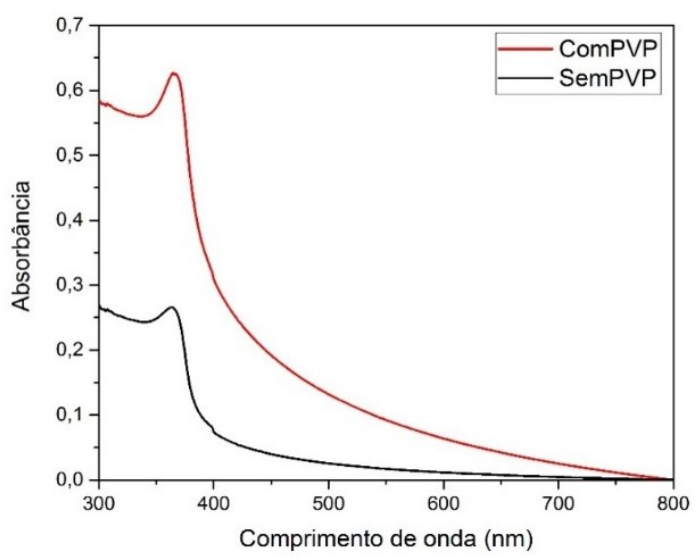

Figura 1: Espectros de absorbância das nanopartículas de óxido de zinco sintetizadas com e sem poli(vinil pirrolidona).

As análises de DRX foram realizadas com o objetivo de se caracterizar a estrutura cristalográfica do produto obtido e, mediante comparação com difratogramas publicados na literatura, confirmar se o produto sintetizado era realmente óxido de zinco. Na Figura 2 são apresentados os difratogramas de raio-X para as amostras sintetizadas com e sem poli(vinil pirrolidona). Todos os picos de difração de Bragg, devidamente especificados nos difratogramas, são típicos de cristais de óxido de zinco com estrutura hexagonal (wurtzita), conforme reportado na literatura [15] e [17]. A não existência de picos extra demonstram que os nanocristais de óxido de zinco sintetizados possuem elevado grau de pureza, e a cristalidade do material parece não ter sido afetada pela adição do agente estabilizante poli(vinil pirrolidona) durante o processo de síntese.

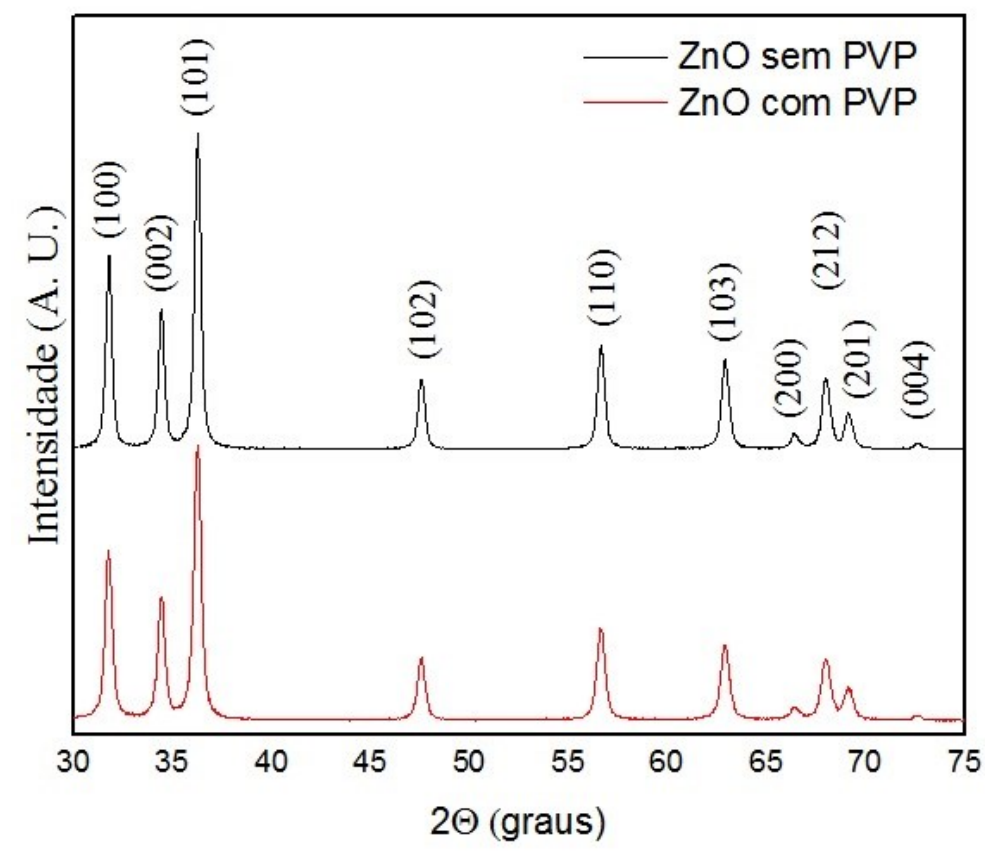

Figura 2: Difratogramas de raios-X das nanopartículas de óxido de zinco sintetizadas com e sem poli(vinil pirrolidona).

Os difratogramas de raios-X também foram utilizados para se estimar o tamanho médio dos cristalitos de acordo com a fórmula de Scherre [16], mostrada na equação 4. Nesta equação, $\lambda$ é o comprimento de onda dos raios-X utilizado $(1,5406 \AA$ ), $k$ é um parâmetro de forma das nanoestuturas (considerado 0,9 devido a forma esferulóide dos cristalitos), $\beta$ é o valor da largura a meia altura do pico de máxima intensidade de difração de Bragg (100), localizado em torno de $36,28^{\circ}$, e $\theta$ é o valor da metade do ângulo $2 \theta$ referente ao pico de máxima intesidade de difração de Bragg. O tamanho dos cristalitos estimado pela fórmula foi de $23 \mathrm{e}$ $21 \mathrm{~nm}$ para as nanopartículas de óxido de zinco sintetizadas sem e com poli(vinil pirrolidona), respectivamente. Estes resultados demonstram que houve pouca influência do agente estabilizante na 
cristalinidade das nanopartículas de $\mathrm{ZnO}$ produzidas na ausência e presença do agente estabilizante.

$$
D=\frac{k \cdot \lambda}{\beta \cdot \cos (\theta)}
$$

As análises de MEV-FEG e MET foram realizadas para avaliar a forma geométrica e o tamanho médio das nanopartículas de óxido de zinco sintetizadas. Como é possível notar a partir da Figura 3, e principalmente a partir da Figura 4, as características morfológicas das nanopartículas visualizadas nas imagens de microscopia são condizentes com as estimativas de tamanho obtidas a partir dos cálculos de tamanho de cristalito obtidas por DRX. Nas imagens presentes na Figura 3, apesar das nanopartículas estarem muito aglomeradas por estarem na forma de um fino pó seco, observa-se uma distribuição razoavelmente homogênea de tamanho das partículas situado em torno de $50 \mathrm{~nm}$, o que significa que cada partícula é composta por no máximo 3 cristalitos.
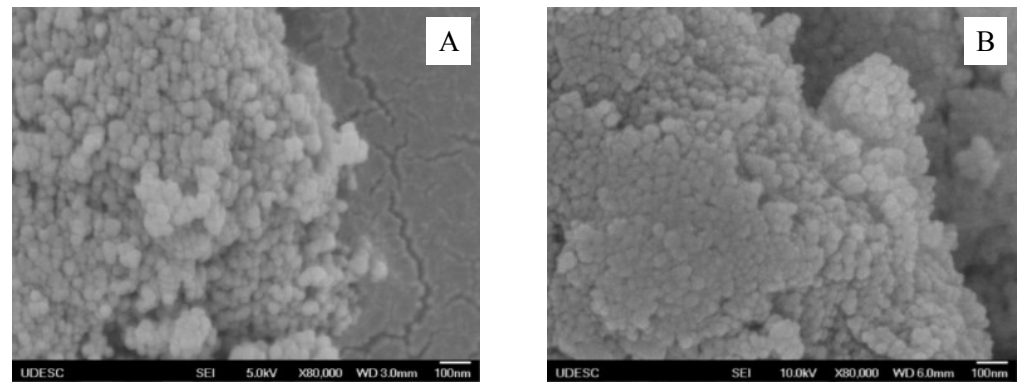

Figura 3: Imagens obtidas por MEV-FEG das nanopartículas de óxido de zinco produzidas: A) sem poli(vinil pirrolidona); B) com poli(vini lpirrolidona) com aproximação de 80.000x.
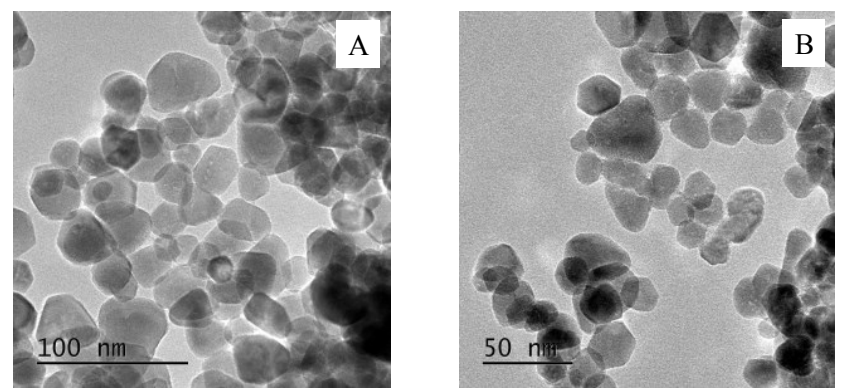

Figura 4: Imagens obtidas MET das nanopartículas de óxido de zinco produzidas: A) sem poli(vinil pirrolidona); B) com poli(vini lpirrolidona).

Por fim, a eficiência antibacteriana das nanopartículas de óxido de zinco sintetizadas sem poli(vinil pirrolidona) foi avaliada contra a bactéria Gram negativa Escherichia coli. Os resultados apresentados na Figura 5 mostram claramente que concentrações a partir de $50 \mathrm{mg} . \mathrm{L}^{-1}$ foram suficientes para inibir por completo o crescimento das bactérias $E$. coli.
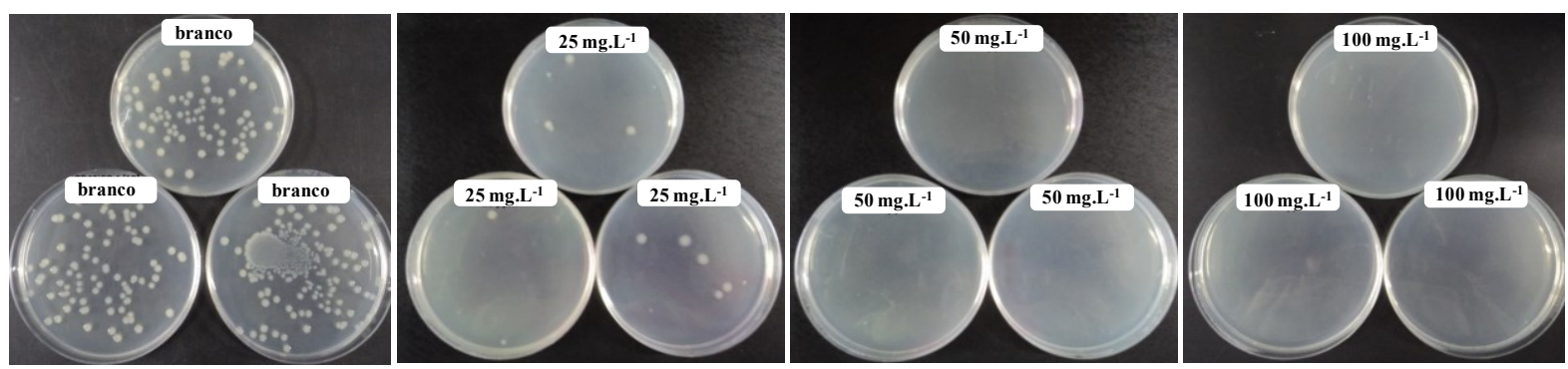

Figura 5: Resultados da quantidade de unidades formadoras de colônia (UFC) obtida nos ensaios antibacterianos conduzidos na presença de $0,25,50$ e $100 \mathrm{mg} . \mathrm{L}^{-1}$ das nanopartículas de óxido de zinco sintetizadas sem poli(vinil pirrolidona). 


\section{CONCLUSÕES}

O presente trabalho avaliou a rota química do poliol para sintetizar nanopartículas de óxido de zinco, investigando a influência da presença do agente estabilizante poli(vinil pirrolidona) no meio reacional sobre as características morfológicas das nanopartículas produzidas. Os resultados obtidos demonstraram que em ambos os casos foi possível produzir nanopartículas de óxido de zinco com forma geométrica tendendo à esférica, com tamanhos médios em torno de $50 \mathrm{~nm}$, compreendendo no máximo 3 cristalitos da ordem de 20 $\mathrm{nm}$ por partícula. Os ensaios microbiológicos realizados indicaram que concentrações de $50 \mathrm{mg} . \mathrm{L}^{-1}$ de óxido de zinco nanoparticulado foram suficientes para inibir por completo o crescimento da bactéria Gram negativa Escherichia coli, demonstrando que a rota química do poliol pode ser usada na produção deste tipo de nanomaterial para garantir um bom desempenho antibacteriano em processos de desinfecção da água.

\section{AGRADECIMENTOS}

Os autores agradecem à UNIVILLE pelo suporte financeiro.

\section{BIBLIOGRAFIA}

[1] COUTO, G. G. Nanopartículas de níquel: sintese, caracterização, propriedades e estudo de sua utilização como catalisadores na obtenção de nanotubos de carbono, Dissertação de M.Sc., Departamento de Química, Universidade Federal do Paraná, Curitiba, Paraná, 2006.

[2] NOGUEIRA, A.L., MACHADO, R.A.F., DUTRA, G.B., et al., "Synthesis and Characterization of Silver Nanoparticles Produced with a Bifunctional Stabilizing Agent", Ind. Eng. Chem. Res., v. 53, pp. 3426-3434, 2014.

[3] BAGCHI, B., KAR, S., DEY, S.K., et al., "In Situ Synthesis and Antibacterial Activity of Copper Nanoparticle Loaded Natural Montmorillonite Clay Based on Contact Inhibition and Ion Release", Colloid. Surface. B, v. 108, pp. 358-365, 2013.

[4] LIU, Y., HE, L., MUSTAPHA, A., et al. "Antibacterial Activities of Zinc Oxide Nanoparticles Against Escherichia coli O157:H7”, J. Appl. Microbiol., v. 107, pp. 1193-1201, 2009.

[5] XING, Y., LI, X., ZHANG, L., et al.," Effect of TiO2 Nanoparticles on the Antibacterial and Physical Properties of Polyethylene-Based Films", Prog. Org. Coat., v. 73, pp. 219-224, 2012.

[6] TALEBIAN, N., AMININEZHAD, S.M., DOUDI, M. "Controllable Synthesis of ZnONanopeticles and Their Morphology-Dependent Antibacterial and Optical Properties", J. Photoch. Photobio. B, v. 130, pp. 132-139, 2014.

[7] SALIANI, M., JALAL, R., GOHARSHADI, E.K. "Effect of $\mathrm{pH}$ and Temperature on Antibacterial Activity of Zinc Oxide NanofluidAgainstEschericia coli O157:H7 and Staphylococcus aureus Jundishapur “, $J$. Micobiol, v.8, n.2, 2015.

[8] TALEBIAN, N., ZAVVARE, H.S.H. "Enhanced Bactericidal Action of SnO2 Nanostructures Having Different Morphologies Under Visible Light: Influence of Surfactant"., J. Photoch. Photobio. B, v. 120, pp. 66-73, 2013.

[9] MUÑOZ, M.M. Síntese e caracterização das propriedades estruturais e morfológicas de nanopartículas de ZnO. 2013. Dissertação de Mestrado, Departamento de Física, Universidade de Brasília, Brasília, 2013.

[10] HATZIGRIGORIOU, N.B., PAPASPYRIDES, C.D. "Nanotechnology in Plastic Food-Contact Materials", J. Appl Pol. Sci., v. 122, pp. 3720-3739, 2011.

[11] BELL, M.F. Atividade Antimicrobiana de Cimentos de Ionômero de Vidro Modificados por Nanopartículas deóxido de zinco, Dissertação de M.Sc., Departamento de Odontologia, Universidade Estadual Paulista, Araraquara, 2014.

[12] LV, Y., LIU, H., WANG, Z., et al., "Silver Nanoparticle-Decorated Porous Ceramic Composite for Water Treatment", J. MembraneSci., v. 331, pp. 50-56, 2009.

[13] CABALA, G.V.E. Desenvolvimento de Filtros Cerâmicos Impregnados com Nanopartículas de Prata para Desinfecção de Água para Consumo Humano Contaminada com Bactéria Fecal, Tese de D.Sc, Programa de Pós Graduação em Ciência e Tecnologia de Materiais, Universidade Federal do Rio Grande do Norte, Natal, 2013.

[14] GUTIERREZ, A.M., HOTZA, D., DUTRA, G.B., et al., Rice Husk Ash Impregnated with Silver Nanoparticles for Water Purification, Mat. Sci. Forum, v. 798-799, pp. 727-731, 2014. 
[15] LEE, S., JEONG, S., KIM, D., et al.,"ZnO Nanoparticles with Controlled Shapes and Sizes Prepared Using a Simple Polyol Synthesis”, Superlattice. Microst., v. 43, pp.330-339, 2008.

[16] TUZEMEN, E.S., ELAGOZ, S., SAHIN, H., et al., "Effects of Annealing on Reflectance of ZnO Grown by PFCVAD”, Fen BilimleriDergisi, v. 25, n.2, pp. 41-50, 2013.

[17] ZANATTA, C.S. Preparação e Caracterização de Óxido de Zinco Nanoestruturado. Dissertação de M.Sc., Programa de Pós Graduação em Ciência e Tecnologia de Materiais, Universidade Estadual Paulista, Bauru, 2009. 